\title{
Simulation on Heavy Oil Production from Steam-Flooding
}

\author{
Suthon Srochviksit and Kreangkrai Maneeintr \\ Carbon Capture, Storage and Utilization Research Laboratory, Department of Mining and Petroleum Engineering, Faculty of Engineering, \\ Chulalongkorn University, 10330 Bangkok, Thailand
}

\begin{abstract}
Heavy-oil is one of the main energy sources in the future. However, with the high viscosity of heavy oil, steam-flooding (SF) is one of the major techniques to produce this oil. To determine a favorable operating condition, many recent studies have evaluated the different methods like varying the well spacing and steam injection rates. However, there is no single optimum value for all reservoirs or all modes of operation. In this study, it's aimed to investigate the effects of well spacing, injection rate, and perforation on heavy oil production with low permeability in multi-layered heterogeneous reservoir. The practical field data was applied to simulate the SF process by using STARS, a CMG program. Production parameters such as injector - producer (inj. - prod.) distance from $141 \mathrm{~m}$ to $282 \mathrm{~m}$ and steam injection rates from $30 \mathrm{~m} 3 / \mathrm{d}$ to $180 \mathrm{~m} 3 / \mathrm{d}$ were evaluated to obtain the optimum conditions with $80 \%$ steam quality. The entire project was considered for 20 years of production. From the results, it showed that the higher oil recovery can be achieved by increasing injection rate and/or shorten well spacing. In order to lower the steam consumption, the selective perforation in bottom layers was compared with full perforation strategy. With the balance between oil production and steam injection, about $60 \%$ of steam can be saved in terms of water barrels (bbls). Meanwhile, it's possible to achieve a longer project life due to the slow depletion rate.
\end{abstract}

\section{Introduction}

Steam injection is one of the most successful enhanced oil recovery techniques for heavy oil production. However, the drawback of heavy oil is the high viscosity thus making it difficult and expensive to produce. To overcome this problem, steam-flooding (SF) is applied to produce this oil [1]. Injected steam heats the formation around the well-bore to reduce the oil viscosity and recover towards the producing wells.

In terms of the production effectiveness, steam must be injected at sufficient rates [2]. Moreover, a proper flood pattern can provide good sweep efficiency and more producers to achieve high rates. Chu [8] compared the 5-spot pattern with inverted 7-, 9-, and 13-spot patterns. He found that the oil recovery in a 5-spot (normal or inverted) is the best based on the assumptions that the drainage areas of all producers are the same and that the steam rate is proportional to the pattern size. Therefore, inverted 5-spot pattern was also applied in this study (Fig. 1).

Steam-Oil Ratio (SOR) is a parameter used to monitor the efficiency of oil production with respect to steam injection. The lower SOR, the more efficient steam is utilized. However, maximum oil recovery or high recovery factor $(\mathrm{RF})$ is also favorable to be considered as one of the decision criteria. Although the heat balance model demonstrated that oil/steam ratios are improved with increased steam quality [3], the steam injection rate is a significant parameter to affect the performance of team injection. In general, higher oil recovery can be achieved by higher injection rate, but it is required more energy consumption for steam generation. Also, well spacing is another critical consideration affecting the efficiency and the number of well drills [4]. The more wells drilled, the more fuel energy consumption and hence the higher project cost could be accounted. Also, the heat transfer would be poor due to heat loss if the distance between injectors and producers is far away [5]. Apart from that, the strategy of selective perforation was tested and compared in the modeling studies.

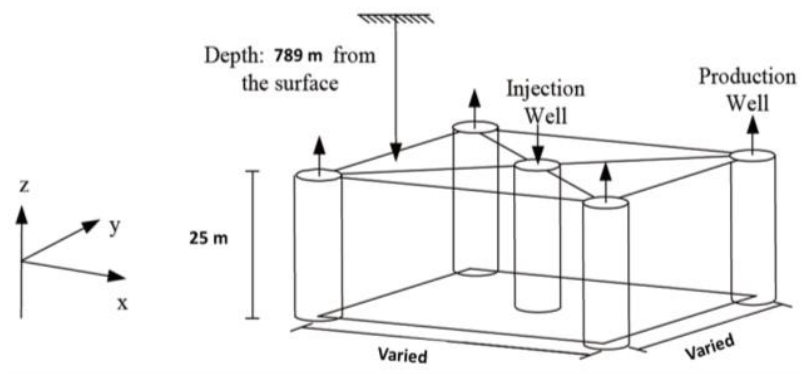

Figure 1. Schematic diagram of inverted 5-spot pattern.

Due to the reservoir heterogeneity, Hong [6, 7] concluded that no single value of steam injection rate or quality can be optimum for all reservoirs or all modes of operation. As such, the same set of values should not be used in all reservoirs. Therefore, in this nameless heterogeneous heavy oil reservoir, a hypothetical study 
has been performed in order to evaluate the favorable SF conditions such as well spacing, injection rate, and number of perforations based on this particular field data by using simulation model.

\section{Simulation}

\subsection{Reservoir model}

All simulation studies were performed by $\mathrm{CMG}$ simulator. Multi-layered heterogeneous reservoir was constructed from the actual field data as shown in Table 1. By calculating the average permeability and porosity from the low permeability zone of the field, totally 5 interested layers are selected for this study. Depending on the well spacing, the grid dimension in $5 \times 5 \times 5,7 \times 7 \times 5$, and 9 x 9 × 5 were created for 3 different injector-producer distance, $141.4 \mathrm{~m}, 212 \mathrm{~m}$, and $282.8 \mathrm{~m}$, respectively. Inverted 5-spot pattern with $80 \%$ steam quality was used in this study. These three different well spacings were evaluated by considering the production efficiency and $\mathrm{RF}$ with various injection rates. The simulation was run by four different injection rates at $30 \mathrm{~m}^{3} / \mathrm{d}, 60 \mathrm{~m}^{3} / \mathrm{d}, 120$ $\mathrm{m}^{3} / \mathrm{d}$, and $180 \mathrm{~m}^{3} / \mathrm{d}$ with those three well spacing cases separately. Initially, full perforation of 5 layers was run in these twelve cases. In order to compare the results consistently and dynamically with the strategy of selective perforation, the same sets of cases (another twelve cases) were simulated by opening the layer 4 and 5 only, where the permeability and porosity are relatively higher than other layers. The reservoir model is illustrated in Fig. 2.
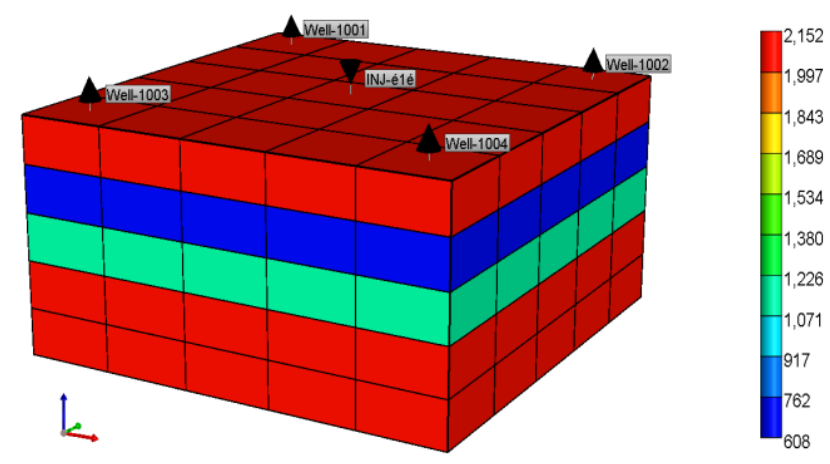

Figure 2. Reservoir model simulation: Permeability, model configuration, and wells location.

Table 1. Operating parameters for simulation

\begin{tabular}{ll}
\hline Operating Conditions & Values \\
\hline Grid dimension (block) & $\begin{array}{l}(5 \times 5 \times 5) ;(7 \times 7 \times 5) ;(9 \\
\text { x } 9 \times 5) \\
\text { Grid size (m) }\end{array}$ \\
Top of reservoir (m) & 789 \\
Depth of well (m) & 25 \\
Effective porosity (\%) & $26-31$ \\
Horizontal permeability (md) & $608-2152$
\end{tabular}

$\begin{array}{ll}\text { Vertical permeability }(\mathrm{md}) & 608-2152 \\ \begin{array}{l}\text { Initial oil saturation }(\%) \\ \text { Initial water saturation }(\%)\end{array} & 80 \\ \begin{array}{l}\text { Reference pressure at datum } \\ \text { depth }(\mathrm{kPa})\end{array} & 8000 \\ \text { Fracturing Pressure }(\mathrm{kPa}) & 11066-12713.9 \\ \text { Reservoir Pressure }(\mathrm{kPa}) & 7825.8 \\ \text { Reservoir temperature }\left({ }^{\circ} \mathrm{C}\right) & 62.78 \\ \text { Oil gravity }(\mathrm{API}) & 23.9 \\ \text { Oil Viscosity }(\mathrm{cP}) \text { at } 25^{\circ} \mathrm{C} & 2075\end{array}$

Since one of the tasks is to evaluate the perforation strategies, oil RF and cumulative SOR would be the factors for comparison. All in all, the various steaminjection rates from $30 \mathrm{~m}^{3} / \mathrm{d}$ to $180 \mathrm{~m}^{3} / \mathrm{d}$ and well spacings were evaluated for different scenarios as proposed in the following:

1. Scenario 1 - Full perforation in all layers. The inverted 5-spot steam-flooding is injected and produced from layer 1 to layer 5 starting from the first day to the end of 20 years.

2. Scenario 2 - Selective perforation in bottom layers. The inverted 5-spot steam-flooding is injected and produced from layer 4 to layer 5 starting from the first day to the end of 20 years.

\section{Result and discussion}

\subsection{Effect of well spacing}

From the result of 3 different injector-producer distances, the shorter the distance provides higher oil recovery than the longer distance. However, the cumulative SOR is decreasing with the increasing distance. In general, both perforation scenarios showe the same trend of this result.

\subsection{Effect of steam injection rates and perforation strategy}

Regarding the full perforation scenario, Fig. 3 and Table 2 exhibit the effects of total oil recovery and the cumulative SOR for various steam injection rates. It's noted that the higher the steam injection rate can increase both the total oil recovery and SOR. Considering together with the well spacing, the injection rate at $180 \mathrm{~m}^{3} / \mathrm{d}$ yields the highest RF at $46.6 \%$ if injector - producer distance is $141.4 \mathrm{~m}$. However, the cumulative SOR is also the highest which means the cost of steam would be higher as well.

Regarding the selective perforation scenario, Fig. 4 and Table 3 exhibit the effects of total oil recovery and the cumulative SOR for various steam injection rates. It's observed that the oil recovery is increasing with the injection rate increased from $30 \mathrm{~m} 3 / \mathrm{d}$ to $60 \mathrm{~m} 3 / \mathrm{d}$ for injector - producer distance at $212 \mathrm{~m}$ and $282.8 \mathrm{~m}$. When the injection rate rises to $120 \mathrm{~m} 3 / \mathrm{d}$ and $180 \mathrm{~m} 3 / \mathrm{d}$, the RF 
does not increase and the value is the same as the case of $60 \mathrm{~m} 3 / \mathrm{d}$. Similarly, the oil recovery is increasing with the injection rate increases up to $120 \mathrm{~m} 3 / \mathrm{d}$ for injector producer distance at $141.4 \mathrm{~m}$. Its RF keeps at the same value as the case of $120 \mathrm{~m} 3 / \mathrm{d}$.

Based on such phenomenon, it can be interpreted that the maximum injection rate cannot be reached during the 20 years period for selective perforation scenario, especially in longer well spacing. That means the bottomhole pressure is still high during the period because higher steam injection rate provides more volume of fluid to the reservoir and hence the pressure can be maintained.

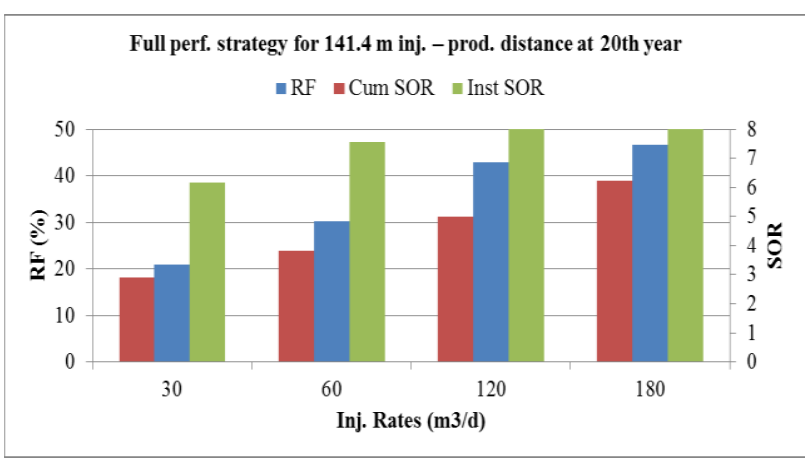

Figure 3. Result of full perforation for $141.4 \mathrm{~m} \mathrm{inj.} \mathrm{-} \mathrm{prod.}$ distance at 20 th year.

Table 2. Numerical results of full perforation for $212 \& 282.8$ $\mathrm{m}$ inj. - prod. distance at $20^{\text {th }}$ year

\begin{tabular}{|c|c|c|c|c|c|c|}
\hline & \multicolumn{3}{|c|}{$\begin{array}{l}\text { Inj. - Prod. Distance: } \\
212 \mathrm{~m}(7 \times 7 \text { full perf. })\end{array}$} & \multicolumn{3}{|c|}{$\begin{array}{l}\text { Inj. - Prod. Distance: } \\
282.8 \text { m (9x9 full perf.) }\end{array}$} \\
\hline $\begin{array}{l}\text { Inj. Rate } \\
\left(\mathrm{m}^{3} / \mathrm{d}\right)\end{array}$ & $\begin{array}{l}R F \\
(\%)\end{array}$ & $\begin{array}{l}\text { Cum. } \\
\text { SOR }\end{array}$ & $\begin{array}{l}\text { Inst. } \\
\text { SOR }\end{array}$ & $\begin{array}{l}R F \\
(\%)\end{array}$ & $\begin{array}{l}\text { Cum. } \\
\text { SOR }\end{array}$ & $\begin{array}{l}\text { Inst. } \\
\text { SOR }\end{array}$ \\
\hline 30 & 14.30 & 2.11 & 4.48 & 10.71 & 1.66 & 3.29 \\
\hline 60 & 19.80 & 2.87 & 5.78 & 14.47 & 2.28 & 4.64 \\
\hline 120 & 26.28 & 3.66 & 6.74 & 17.45 & 2.78 & 4.98 \\
\hline 180 & 28.03 & 3.90 & 6.87 & 17.47 & 2.79 & 5.22 \\
\hline
\end{tabular}

Partial perf. strategy for $141.4 \mathrm{~m}$ inj. - prod. distance at 20th year $\because \mathrm{RF} \quad$ aCum SOR $\quad$ Inst SOR

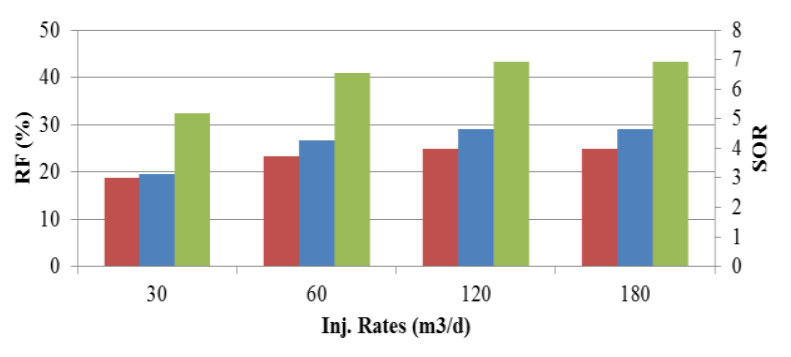

Figure 4. Result of partial perforation for $141.4 \mathrm{~m}$ inj. - prod. distance at 20 th year.

In other words, the oil recovery should increase with the increase of injection rate if the end time of project is longer than 20 years. In this study, project time was considered in 20 years only as the objective is to compare the scenarios between full perforation and selective perforation based on the particular field data. Furthermore, the effects of varying different operating parameters can be fully observed in the full perforation strategy.

Table 3. Numerical results of partial perforation for $212 \&$ $282.8 \mathrm{~m}$ inj. - prod. distance at $20^{\text {th }}$ year

\begin{tabular}{|c|c|c|c|c|c|c|}
\hline & \multicolumn{3}{|c|}{$\begin{array}{r}\text { Inj. - Prod. Distance: } \\
212 \mathrm{~m}(7 \mathrm{x} 7 \text { partial } \\
\text { perf.) }\end{array}$} & \multicolumn{3}{c|}{$\begin{array}{c}\text { Inj. - Prod. Distance: } \\
282.8 \mathrm{~m} \text { (9x9_partial } \\
\text { perf.) }\end{array}$} \\
\hline $\begin{array}{c}\text { Inj. Rate } \\
\left(\mathrm{m}^{3} / \mathrm{d}\right)\end{array}$ & $\begin{array}{c}\text { RF } \\
(\%)\end{array}$ & $\begin{array}{c}\text { Cum. } \\
\text { SOR }\end{array}$ & $\begin{array}{c}\text { Inst. } \\
\text { SOR }\end{array}$ & $\begin{array}{c}\text { RF } \\
(\%)\end{array}$ & $\begin{array}{c}\text { Cum. } \\
\text { SOR }\end{array}$ & $\begin{array}{c}\text { Inst. } \\
\text { SOR }\end{array}$ \\
\hline 30 & 12.76 & 2.22 & 4.09 & 9.14 & 1.74 & 3.11 \\
\hline 60 & 15.37 & 2.62 & 4.76 & 9.76 & 1.93 & 3.49 \\
\hline 120 & 15.37 & 2.62 & 4.83 & 9.76 & 1.93 & 3.49 \\
\hline 180 & 15.37 & 2.62 & 4.83 & 9.76 & 1.93 & 3.49 \\
\hline
\end{tabular}

\section{Conclusion}

Steam-flooding provides efficiently ultimate oil recovery for heavy oil. However, the huge energy consumption can impact to the production efficiency as well as project economics. Although the higher oil recovery could be obtained by increasing the steam injection rate and/or shorten the well spacing, the higher SOR would impact to the project cost at the same time. In terms of oil recovery, injection rate at $180 \mathrm{~m}^{3} / \mathrm{d}$ and injector - producer distance in $141.4 \mathrm{~m}$ gave the best RF in this study. In contrast, injection rate at $30 \mathrm{~m}^{3} / \mathrm{d}$ and injector - producer distance in $282.8 \mathrm{~m}$ gave the best result in terms of SOR. In comparison with the full perforation for injector producer distance in $141.4 \mathrm{~m}$, the selective perforation scenario can save about $60 \%$ of steam with the balance between oil production and steam injection. Besides, the project life can be lengthened by slow reservoir depletion. It's because the high injection rate and less perforation zone can yield a stronger pressure to the field. This can be expressed by the aforesaid numerical results that both $\mathrm{RF}$ and Cum SOR remained in the same value with the increasing of injection rate at the $20^{\text {th }}$ year. As such, it may be a better option if high cash flow is not critical in the early stage of the project.

\section{Acknowledgment}

The authors would like to gratefully acknowledge Chevron Thailand Exploration and Production Ltd., for financial support of this project.

\section{References}

1. Chierici, Gian Luigi. Enhanced Oil Recovery Processes: A State-of-the-Art Review. Azienda generale italiana petroli, (1980)

2. Ali, S. M., and R. F. Meldau. Current Steamflood Technology. Journal of Petroleum Technology 31, 10 $1-332$ (1979) 
3. G.L. Messner, A Comparison of Mass Rate and Steam Quality Reductions to Optimize Steamflood Performance. SPE Annual Technical Conference and Exhibition. Society of Petroleum Engineers, (1990)

4. Roberts, Tom. Economics of Well Spacing, (1961)

5. Doscher, Todd M., and Iraj Ershaghi. Current Economic Appraisal of Steam and Combustion Drives. SPE Symposium on Improved Methods of Oil Recovery. Society of Petroleum Engineers, (1978)
6. K.C. Hong, Effects of Steam Quality and Injection Rate on Steamflood Performance. SPE Reservoir Engineering, 9, 290-296 (1994)

7. K.C. Hong, Steamflood Reservoir Management: Thermal Enhanced Oil Recovery. PennWell Books, (1994)

8. Chu, Chieh. "Pattern configuration effect on steamflood performance." Journal of Petroleum Technology 31, 09 1-101 (1979) 